\title{
ADVANCING THROUGH RETREATING: SELF-CARE AMONG HELPING PRACTITIONERS
}

\author{
E Layton and K Collins \\ University of Cape Town
}

\begin{abstract}
The research was conducted in Cape Town amongst a non-probability sample of 16 helping practitioners who are also retreatants. A literature review describes the value of retreats and retreating and informs the empirical study. The review supports the view that helping practitioners have not only the ability but also a duty to care for themselves The empirical research explores respondents' perceptions and explanations of their retreating experience, using their own words. Six themes surrounding the meaning of retreating emerged from the data. A discussion of findings identifies the efficacy of retreating as a self-care tool among helping practitioners. Retreatants yearn for recuperative silence and reflective opportunities that remedy the stresses and pace of modern living. By retreating, they experience not only an avoidance of burnout but also an enhancement of functioning and well-being. The tools used on retreat have as much value outside the retreat setting as in it. Eight recommendations encourage the development of self-awareness and self-care practices related to retreating, including making space for this development in the workplace.
\end{abstract}

\section{RESEARCH QUESTIONS}

Firstly, what does "retreating" mean to helping practitioners who use this as a self-care tool? (This question also demands an understanding of how retreating differs from other self-care activities of withdrawal, such as holidaying.)

Secondly, why and how is retreating valuable to helping practitioners: what are the personal and professional benefits they experience?

Thirdly, do retreats and/or related practices have a place/function in professional organisations? (This also requires an exploration of what agencies are, or could be, doing to promote caregivers' wellness.)

\section{GOALS OF THE RESEARCH}

The goals of the research were to: 1) identify the needs for and value of the retreating experience by reviewing literature on the topic and 2) explore the utilization of the retreating experience by a local sample of helping professionals, in order to answer the research questions.

\section{CARING FOR THE CARER}

In accepting a core concept of the ethic of care (Sevenhuijsen 2003) that we respond to caregivers' needs as well as to those of the care receiver, we can argue that effective caregivers will not only want to enhance their clients' well-being, but will be as committed to their own personal wellness. Paul Wilkins (1997:9-10), writing on personal and professional development among counsellors, notes that personal growth is "...about resourcing ourselves so that we have the energy and enthusiasm that effective work demands. Personal growth includes an obligation ... to care for the self of the therapist." Caring for the self is also advocated by transpersonal psychologist, Abraham 
Maslow (1968, in Hart 2001:12-13) who urges self-actualisation: a conscious and continual "movement toward increasing wholeness". This means that it is not enough that we merely adjust to the dynamics of our inner/outer world. We need to reflect, analyse, understand and learn how to be with our own experiences (Welwood 2000). We need to use our wisdom, will and willingness to engage with our multi-dimensional selves: to face our fears and freedoms, to respect and fulfil our responsibilities, to transcend the limitations of personality and ego. This speaks of a proactive search for meaning and purpose in life. Exploring/discovering who we are, how we are, and why we are as we are, is a journey of self-awareness and growth that has intra-, inter- and transpersonal benefits. As Hart (2001:13) notes, personal “...transformation often catalyses growth that extends beyond the individual".

Maslow also believes that everyone has innate spiritual needs and yearning, and that psychological health is rooted in a "...well integrated, deep sense of spirituality in life" (Vaughan, 1991:105). One's spiritual awareness and experience is "....an important determinant of subjective well-being, and thus, of quality of life and health care outcomes" (Mount, Lawlor \& Cassell, 2003:303). Genuinely caring for others involves a spiritual dimension (Montgomery, 1991). The carer's capacity to experience this dimension in the client/worker relationship not only "...distinguishes caring from ... over-involvement, rescuing or co-dependency", but also influences whether the caregiver "...experiences personal fulfilment, or emotional depletion" in the act and relationship of helping. When a caregiver has awareness that $\mathrm{s} / \mathrm{he}$ is "...in relationship [with] ... a force greater than [her/him] self ... [this] serves as an important resource for self-renewal and motivation for the caregiver, so that caring is associated with profound fulfilment and growth rather than burnout." (Montgomery, 1991:92-93). One resource that benefits personal, professional and spiritual selfcare and development is that of retreating.

\section{PURPOSES AND BENEFITS OF RETREATING}

Retreating serves many purposes and offers many benefits. Philosopher Paul Brunton (1984:28) urges that "there is a real need to balance our extreme tendency to activism with something of quietism, to offset our excessive doing with deeper being". Louden (1997), writing specifically about retreats, advocates the need to balance periods of task/achievement/goal orientation with periods of reflective privacy in which to revive the depleted self and reclaim one's authentic self. Retreating also has a preventative value - namely, the prevention of stress, physical illness, psychosocial disempowerment and spiritual anomie (Psychology Today, 1993). It can reflect a critical/urgent transpersonal endeavour (Schofield, 1927) and offer mystical experiences and flashes of cosmic consciousness (Delaney, 1992 reviewing; Louden, 1997).

Historically, rituals of retreating date back to $6000 \mathrm{BCE}$ (Louden, 1997). It has long been an integral practice of the Buddhist, Christian, Hindu, Islamic and Judaic religions (Delaney, 1992). Yet today's retreatants do not necessarily hold religious beliefs. Retreating is nowadays more a “...desire for silence, solitude and reflection" (Housden, 1995:1).

\section{FORMS OF RETREATING}

Retreats can take many forms. Louden (1997) recognises momentary retreats (2 minutes of visualisation and self-affirmation), mini-retreats ( $<1$ day) and long retreats ( $>2$ days). Retreats can be shared with others or undertaken in complete silence/solitude. Religious writers (Schofield 1927; Rahner, 1967; Underhill, 1990) emphasise the devotional, purifying nature of retreats undertaken in religious settings (like monasteries or ashrams). Non-religious writers, on the other hand, note that retreats cannot be limited to one type of experience. Retreats can be religious, 
spiritual, secular or eclectic in nature/form. Retreats can incorporate public spaces (such as wilderness retreats or retreat centres) or private spaces (such as holiday homes) (Louden, 1997).

Retreat venues are now worldwide and diverse (Driedger, McClelland \& Kar 2001). The World Wide Web links to dozens of retreat-related sites. For example, Expand Retreats (2003) lists around 1000 retreat centres in the USA alone. Locally, this study identifies 11 retreat centres all within $2 \frac{1}{2}$ hours' drive of Cape Town.

Retreats can be structured or unstructured, i.e. using time, space and activity in planned or unplanned ways. Furthermore, the many tools and practices of self-care one might use outside the retreat setting, can also be used within it - such as, meditation, prayer, aromatherapy, journal writing, chanting, art, exercise and so on. Hart (2001:145) advocates whatever activities "...may shift attention from the normally dominant chatter of the small self and open the possibility for intuition, insight and imagination."

For caregivers across the spectrum of the helping professions, Louden's non-denominational definition of retreating is apt (1997:12):

"Retreat is about stepping out of your ordinary existence to listen and attune to your truest, most authentic self. It is about being self-referenced to become self-restored. It is about trusting what you experience as sacred without the need for external sanction. It is setting apart time to tend the hearth of your inner life ... to reaffirm your values by giving yourself permission to do what you need when you need it ... about using loving self-discipline ..." (Louden's emphasis)

This definition reiterates that at the heart of every retreat is elected silence, solitude, patience, trust, courage, rest and reflection, as well as the use of mind/emotion/action for psycho-spiritual development (Schofield, 1927; Rahner, 1967; Underhill, 1990; Housden, 1995; Louden, 1997; Driedger et al., 2001).

\section{RETREATANTS}

Using foreign data, the average age of retreatants to America's largest spiritual retreat centre which a decade ago was receiving around 10000 visitors every summer - The Omega Institute - is late 30s and early 40s, and they are drawn from all sectors of society, with women dominating (Psychology Today, 1993).

Retreats and retreating are not always comfortable experiences. The challenges of retreating present themselves even before one's arrival at the retreat space. Women in particular find it difficult to give themselves permission to take time away from the people/demands of their daily lives (Louden, 1997). Retreating can raise feelings of selfishness and guilt. Yet failure to take time for self-care raises the danger of ensnarement in "a tyranny of relationships" and loss of selffulfilment (Louden, 1997:15). Once on retreat, further challenges emerge. These can include boredom, distractions, resistance, confusion, fear, negative mind states; the inability to detach emotionally from one's external life; trouble in emptying/stilling the mind, or not fulfilling one's intention for retreating (Louden, 1997). Then there are also the difficulties associated with confronting the negative/shadow side of oneself (Psychology Today, 1993). Although Louden normalises these difficulties, Cooper (in Louden, 1997:109) notes that "...without a strong will, a person is likely to leave a retreat early". This speaks of the effort required to enter and successfully complete a retreat. Challenges arising after the retreat most often surround the difficulty of reintegration back into the world (Vaughan 1991) and losing too quickly the bio-psycho-spiritual benefits of the retreat (Louden, 1997; Driedger et al., 2001). 


\section{RETREATING FROM THE WORKING ENVIRONMENT}

The secularisation of the workplace has meant that people's innate spiritual dimension is commonly overlooked outside faith-based/religious settings (Hunter, Bailey \& Taylor, 1998). These authors (e.g. Bloom, 1997) urge recognition that organisations cannot promote/sustain wellbeing - in their staff or clients - unless they create "...safe environments which can promote creativity, rational thought, the expression of emotions, and, ultimately, wholeness" (Bloom, 1997:255). Bloom (1997) writes of the need to create "sanctuary" in the workplace: physical spaces offering metaphysical opportunities to enhance holistic wellness.

Some organisations are actively promoting staff retreats/retreating (Driedger et al., 2001). Although we could find no data for SA, in the USA and Canada several police departments as well as the US military offer retreating opportunities to their employees, spouses and families. This is done in recognition that their employees face high expectations for professional conduct in the face of great stresses (Callaway, 2001). Such stresses are not sufficiently alleviated through merely sick/holiday leave. Respect for inner well-being and outer efficacy requires greater attention/effort than just a few days spent at home. Among these agencies, the benefits of staff wellness have justified retreat leave as both a company benefit and an employee imperative in order to rectify stress and enhance productivity.

\section{CONCEPTUALISATION AND OPERATIONALISATION OF THE EMPIRICAL STUDY}

Three concepts require clarification: retreating, self-care and motivation. The denotative meaning was not defined for the respondents. Instead, they were asked for their own unique understanding, and their subjective interpretations are presented and discussed below. "Self-care", however, is regarded as intentional practices aimed at developing/maintaining/enhancing a positive sense of well-being. "Motivation" refers to one's instinctual or learned thoughts/behaviours that direct action. In this study retreating is an acquired motivation, namely, an incentive that is reinforced when certain behaviours bring about desired outcomes.

This qualitative research has both a basic and applied focus. It includes both deductive and inductive components. Deductively, we verify and modify existing knowledge of retreating practice and forms. Inductively, we capture new meaning, descriptions and recommendations, particularly around the professional benefits of retreating, and the considerations of incorporating retreat-type practices in the workplace.

\section{METHODOLOGY}

Sixteen respondents were identified based on convenience, as well as snowball sampling. To qualify for inclusion in this study, all respondents had to:

- Be helping practitioners - either professionals or volunteers;

- Use retreats/retreating as a self-care tool;

- Have retreated at established retreat centres, locally or overseas.

These 16 helping practitioners come from a broad range of fields: prevention, rehabilitation and development practice in health, education and spiritual settings.

The three volunteer helping practitioners include two spiritual "companions":

- both assisting in religious communities;

- with one also working in palliative care and cancer recovery;

- a retired social worker and now volunteer helper at a retreat centre. 
The 11 professional practitioners are:

- a programme manager in the HIV/AIDS field, working in the townships;

- a social worker in the field of addiction-rehabilitation;

- a psychologist and workshop presenter/facilitator in the field of mental health/addictions' recovery;

- a recently retired teacher, now a trainer in adult skills development;

- an educator/group facilitator/consultant in the field of business management development in tertiary education;

- a programme manager and trainer in a tertiary institute concerned with personal growth and counselling skills training;

- a trainer/project co-ordinator for a mental health agency;

- a recently retired nurse and care-giver to the aged;

- a pre-school principal/teacher and workshop presenter in parenting skills;

- a programme manager of community development projects in the townships;

- a social worker; now a strategic planner in an educational-spiritual community.

The two practitioners of alternative/complementary care-giving practices are:

- an aromatherapist and reiki practitioner;

- an astrologer and leader of self-awareness workshops and retreats.

Data were collected by a focus group to raise consciousness of the issues surrounding retreating, individual interviews to explore the issues more deeply and self-administered questionnaires to collect descriptive details.

TABLE 1

TYPE OF RETREATS UNDERTAKEN

\begin{tabular}{|l|c|}
\hline Retreat type & No. of respondents \\
\hline Group retreats & 14 \\
\hline Individual/solo retreats & 14 \\
\hline Silent retreats 1 & 13 \\
\hline 3+ day retreats & 12 \\
\hline 2-day retreats & 7 \\
\hline 1-day retreats & 7 \\
\hline Buddhist retreats & 7 \\
\hline Wilderness retreats & 4 \\
\hline Christian retreats & 2 \\
\hline Indulgent retreats ${ }^{2}$ & 2 \\
\hline "Sweat lodge" retreats ${ }^{3}$ & 1 \\
\hline
\end{tabular}

1 Can be undertaken in groups or individually.

2 The nature of this retreat is an emphasis on nurturing oneself in whatever ways seem appropriate. This would likely exclude any ascetic or structured or self-confrontational practices, but rather be a time of withdrawal from normal routines in order to indulge oneself in the retreat-type activities that give pleasure: e.g. sleep, relaxation, art, music, play/fun, experiencing community rather than solitude.

3 Originally a Native American Indian cleansing/purification/transformation ritual, undertaken in a group, usually over a 34 day period. 


\section{Analysis of data}

\section{Data are categorised into six themes:}

1. The meaning and importance of retreating;

2. The tools of retreating for self-care;

3. The challenges of retreating;

4. The benefits of retreating;

5. The impact of retreating on one's care-giving abilities and practice;

6. The place/role of retreat-type practices within helping agencies.

\section{Theme 1. The meaning and importance of retreating}

Respondents were questioned as to the meaning, purpose and importance of retreating as a selfcare tool. They agreed that retreating means a time of temporary withdrawal from one's typical routines, into a time/space of quiet, meditative self-reflection:

It's a time to withdraw from the busyness of daily life and to reflect on where I'm at, and to go within, ... and if there are any issues I'm struggling with then to take time out to look at them, explore them.

Retreating for me is about retreating into [one] self. ... It's a place where I can ... reconnect with that part of myself that is quite neglected ...

All respondents were clear that retreating is very different from other activities of withdrawal oneself from daily life, such as holidaying. The difference lies in the purpose, nature and outcome.

It's [one's] intention that makes a difference. [Retreating] ... is a conscious intention to focus onto that deeper layer of being receptive ... and I would certainly put aside a lot of the usual distractions.

All respondents note that their retreating has a spiritual dimension to it, although some place more emphasis on this than others.

... it's also a time for intimacy - with myself, with the deep current of life, and with the Beloved. ... To me retreating is about finding greater union with Life, so [that] when I'm alone, when I'm in silence, I actually feel more my deep connection to other people and life.

It's an opportunity [for] an encounter with God ... to find God waiting there to welcome you. I love that.

Although almost all (14) valued the opportunity for greater rest and sleep whilst on retreat, retreats require effort:

I need very much to have personal [and] marital space too. ... So it's not just a blotting out period ... I do a lot of inner work [on retreat].

For some, at certain times, retreating has elements of escape:

sometimes feel I'm drowning in my everyday life ... so I actually have to remove myself.

Although escape can be a mixed blessing:

It's about running away from the chaos outside [oneself] to explore the chaos inside! 
Yet escape doesn't always mean a 'running away from'; it can also be a 'stepping into' something inviting and rewarding:

I went on retreat because of an awareness that I needed to develop a spiritual discipline ... I actually was seeking a relationship with something far greater - with God - and that I needed to do something about it. ... Maybe a Jungian would say I was seeking a way to connect to my 'true self', but [for me] it was [about] going beyond 'me'.

Fifteen of the 16 respondents regard retreating as very important as a self-care tool for personal well-being:

It is who I am now ... it facilitates my awareness of me, and that is a benefit, because to live who you're not is hell. It is for my own good and I will be the first to say my motives are selfish, because I know that the more I retreat ... the happier I am.

For this reason, all incorporate retreat-type practices into their daily lives:

Yes [retreating is essential for me] but having said that, it's a luxury that I've been able to construct for myself. If I'm not able to go on retreat ... what I do [instead], is take aspects of my retreat practice into my daily life.

\section{Theme 2. The tools of retreating for self-care}

The following table shows the key activities and artefacts of the retreat experience.

The respondents report using almost all of their preferred practices/artefacts outside the retreat space as well, and confirm that if retreating were removed as a self-care option, they would rely on these tools - individually and in combination - to develop/restore/sustain their sense of well-being.

The respondents volunteered additional practices that aid self-care but are not part of their formal retreat experiences, such as gardening, walking and creating sanctuary within one's home.

TABLE 2

THE KEY COMPONENTS OF RETREATS

\begin{tabular}{|l|c|}
\hline \multicolumn{1}{|c|}{ Activity/artefacts used on retreat } & No. of respondents \\
\hline Meditation & All \\
\hline Silence & All \\
\hline Nature & All \\
\hline Solitude & 15 \\
\hline Self-reflection & 15 \\
\hline Sleep/rest & 14 \\
\hline Contemplation & 11 \\
\hline Reading & 11 \\
\hline Exercise & 10 \\
\hline Candles & 10 \\
\hline Journal writing & 9 \\
\hline Prayer & 9 \\
\hline
\end{tabular}




\section{Theme 3. The challenges of retreating}

Retreating presents a number of challenges. The respondents' comments can be summarized as follows.

The difficulties in getting away for a retreat derive from:

- study/work demands that impinge upon weekends;

- time/money constraints;

- responsibilities as a parent/partner;

- feelings of guilt/selfishness, and the struggle to give oneself permission to take time off/away;

- the perception that a weekend is too short to derive meaningful benefit from a retreat;

- the struggle to take time off work.

Many/most difficulties arise during the retreat:

- without internal awareness or external guidance, retreating can easily be a superficial undertaking;

- the difficulties of mentally/emotionally settling down into a retreat;

- entering into periods of unhappiness/desolation/suffering as one confronts the hard parts of one's life and attempts to make meaning of these;

- surrendering one's illusions (e.g. of being in control, being independent);

- confronting one's fears, values, loneliness, grief, despair etc.;

- noticing one's insignificance, one's enormity, one's ugliness, one's beauty;

- allowing the presence/experience of Love to enter;

- the need for long periods of sleep before one can engage with meaningful inner work;

- being distracted mentally by one's worries, responsibilities etc.;

- feelings of guilt/selfishness;

- self-doubt and questioning;

- the physical discomfort of long periods spent in stillness (e.g. during meditation);

- the anxiety and exhaustion that can arise from intense/confrontational inner work;

- the feelings of reluctance, through to rage, when structure is imposed on one from the outside (e.g. by a retreat leader or spiritual director);

- the challenge of being in a state/place of deep and prolonged silence, particularly if one is not accustomed to this;

- the difficulties of not having one's usual "props" to distract one from oneself;

- not being able to easily escape the discomforts of retreating.

Then re-entering the world and returning to one's usual routines on conclusion of a retreat can be problematic because:

- one is immediately drawn/plunged back into busyness; into the harshness of life;

- one feels less defended/protected; 
- it takes skill/experience/sensitivity to know how much, and with whom, to speak of your retreat experience to avoid feeling exposed/misunderstood;

- the inevitable, normal, routine and petty problems of life are waiting for you;

- one's colleagues/family/friends are in a very different frame of mind;

- one is expected to re-enter one's usual roles immediately and effortlessly;

- the activities/awareness/practices of the retreat are not maintained with the same degree of regularity/intensity/application;

- the pressures of time/work etc. immediately resurface;

- the noise of daily living feels intrusive/disturbing to the peace gained on retreat;

- one's heightened self-awareness can be problematic: contributing to sensory "overload", self-criticism or a return to anxious/tense states.

Several respondents mentioned the need to build a transition time into the space between finishing a retreat and re-engaging with the world. For example, two use the drive time between the retreat centre and home or work for mentally/emotionally detaching from the retreat and preparing for the noise and pressures ahead. Others speak of deliberately minimising social engagements for the first couple of days and trying not to get caught up immediately in life's mundane and on-going chores and responsibilities.

Despite the many difficulties described - and some are particularly distressing and uncomfortable - none of the respondents has left a retreat prematurely. All agree that the benefits outweigh the difficulties associated with retreating.

\section{Theme 4. The benefits of retreating}

Fifteen of the 16 respondents have come to regard retreating as an essential self-care tool. The stated benefits are summarised in four categories: physical, mental, psycho-spiritual benefits as well as enhanced capabilities.

\section{Physical benefits}

- Rest and relaxation;

- Reduced physical illness;

- Feeling physically revitalised, re-energised;

- More balanced/healthier consumption.

\section{Mental benefits}

- Stress/anxiety/fear reduction or resolution;

- Slowing down;

- Quietening the mind;

- Giving oneself permission to focus inwards;

- Understanding of self, life events, feelings;

- Mental refreshment, equanimity, equilibrium;

- Temporarily relinquishing the analytic, logical, critical, judgemental, goal-oriented mind;

- Feeling mentally stimulated/alert; 
- New learning (from books, spiritual director, or teachings experienced on retreat);

- Reviewing past/present; recognising the bigger picture, gaining clarity for the future.

\section{Psycho-spiritual benefits}

- Inner stillness, peace, tranquillity, calm, centredness, groundedness;

- Trust, security, strength, protection, cohesion;

- Compassion, tolerance, respect, humility, kindness, patience;

- Self-awareness, insight, mindfulness;

- Acceptance of self/others/life;

- Affirmation, confirmation, validation, motivation;

- Emotional healing, release of shame/hurt;

- Balance and integration between inner/outer, mind/body/spirit, being/doing;

- Freedom from expectations;

- Feelings of joy, love, peace, freedom, fun, celebration of self/life;

- Emotional refuelling;

- Revelation, altered states of consciousness, mystical experiences;

- Perceiving the purpose/meaning/interconnectedness of life;

- Experiencing knowledge of and/or a connection with one's Higher Power (however one understands this term);

- Recognition of one's insignificance and grandeur, one's ugliness and beauty, one's past/present/potential, one's value.

Enhanced abilities. The respondents cited an improved ability to:

- Feel connected (to life/others) whilst simultaneously detached;

- Be clearer about one's personal/professional boundaries;

- Live more authentically/congruently in the world;

- Be more productive at work;

- Turn inward, face oneself, confront one's own shadow/repressed self;

- Cope with one's stresses, demands and pressures;

- Experience a sense of fulfilment;

- Recognise self-oppressive attitudes/practices;

- Love oneself and others more;

- Give easily, and more, to others;

- See things differently, more clearly; find a new perspective;

- Act more spontaneously, respond to one's intuition;

- Dissolve/resolve complex personal issues;

- Make life-changing decisions, clarify goals, discover one's passion;

- Let go of limiting/inflexible/expected beliefs, behaviour or demands; 
- Harness and express one's creativity - often in writing poetry/prose;

- Be active and involved in the world, whilst simultaneously staying connected to one's deepest self;

- Be alone, silent;

- Manage/sustain one's energy levels in order to prevent/reduce depletion or tiredness;

- Avoid/limit vicarious trauma;

- Fine-tune one's values, purpose, direction;

- See, appreciate and respond to nature and beauty (both outer and inner beauty).

Six respondents report the benefits as lasting "for a short while"; three say it lasts "for a long while", whilst five feel they are able to sustain the advantages until their next retreat. Whilst certain benefits were particularly short-lived - feeling physically/mentally rested - others saw each retreat as a building block for accumulative benefit:

I know that it's transformed my life. ... the benefits continually return to remind me they're like visitors - ... that [evoke] 'aha' [moments of awareness] and then I will quieten again, and come back to my centre, and so it's like an underground river that's [constantly] there.

\section{Theme 5. The impact of retreating upon one's care-giving abilities and practice}

This theme explores how retreating as a self-care tool assists the respondents' care-giving capacity, their client-worker relationships, their attitudes to work, their skills and manner of working in a helping environment. Respondents were closely in touch with this dimension in their lives, linking retreating, self-awareness and professional functioning. They spoke fully and eloquently about the impact on their work; three quotes are given below.

My work is totally, deeply involved with people all the time ... I can end up empty on a Friday afternoon, drained .... I've learned how to come back to this work situation and balance it more, [not] get too involved, [not] give away too much of my energy. ... It affects all my relationships ... [I] view everything with much more equanimity ... [I'm] aware of the difficult areas of my personality - my over-perfectionist stuff, people-pleasing things, things I know are my 'traps' ...

I think if I didn't have my half hour [of quiet time daily] and my weekend [retreats] away, I think I'd just be frazzled. ... (She quotes a Dominican priest that) "there are some wounds that only beauty can heal" and I think that's profoundly true. ... We're working in the townships all the time and with conflict which just doesn't end. ... [Retreating helps] keep you in there with the difficulty of that [environment] ... [I'm] able to be close to whatever the damage is without introjecting, being contaminated [myself, or] get[ting] sucked in.

I think if I wasn't self-aware I wouldn't be very good at working with other people. ... It's more than just [awareness of] counter-transference but I feel that the more developed I am as a person, the more equipped I will be to help other people. ... It's about skills that you can only develop through developing self-awareness and through reflecting on yourself and through learning about yourself. It's ... an ability to look at things and ... not to be scared of [doing so]. ... If you've done it [e.g. faced your own shadow] ... you'll be more understanding of what [the clients] are going through. ... The fact that you have experienced something similar [to the client] makes you more able to work with it. ... Because our work is so draining and because our clients are so full of shit, we often will 
have sessions where ... we will sit around and we'll complain about our clients, about our jobs, and about how stressful it is .... [Retreat time] helps me to not be so negative... [because] if I'm not feeling integrated ... I'd be more likely to enter into that [negativity].

\section{Theme 6. The place/role of retreat-type practices within helping agencies}

Fifteen of the respondents regard retreating as a life-skill in their repertoire of personal tools. Many recommend that the practices associated with retreating be encouraged from childhood especially self-awareness/reflection and getting into nature. The respondents would also welcome employers being more aware of their employees' holistic well-being, although not all are optimistic of this being achieved. Others specifically urge that helping practitioners - doctors, psychologists, psychiatrists, social workers, police, correctional services' personnel, teachers, nurses, and counsellors were named specifically - be exposed to these self-care tools.

... we've lost the human side of everything ... and now we see this huge growth in things like retreating and meditation ... because people are lost and they're yearning for something because of the way the world has gone. There's a huge search for this, but ... the humanness [is] being taken out of [the workplace]. ... I think that any people that are in the caring professions [should be retreating] - anyone who thinks they've got all the answers. But they don't always know the [client's] feelings and they don't always know their own feelings. ... You see it with oncologists who haven't confronted their own feelings, and are very cold with their patients, almost cruelly cold, and [who] do things that are almost frightening. ... I find [it] ... interesting that psychologists or psychiatrists ... very rarely address the spiritual dimension of the person and to me the spiritual and psychological are very much tied in.

Three of the respondents - holding management positions within their health settings - are striving to enhance self-care practices among their care-giving staff. One respondent takes her staff on retreat.

... we're busy with strategic planning at the moment, and one of the pillars of this ... plan is the internal care of staff. ... We've devoted a whole section of our work now to "how are we going to care for staff - emotionally, spiritually, in all ways?" ... We're looking at introducing things over the lunch time [period] - therapeutic sessions - such as massage, women's wellness, teaching colleagues about ...looking after yourself.

Yet caution is needed. These same respondents - and more - recognise the challenges of introducing unfamiliar tools and topics to staff and clients where it may be unwanted or threatening.

[Retreating and aligned practices are] not appropriate for everybody; it's only appropriate for some people at certain phases of their lives. ... One has to be wary of assuming that because it works for me and because it excites me and because I get a lot of value from it, therefore it must be that way for everyone else. ... I think it would be very easy to ... become a retreat snob.

Three respondents (one in education, the other two in health) introduce clients to retreat type practices.

As a result of the risks of giving people tools they are not ready for, don't understand, or don't want, the respondents recommend that people be offered structures/space/activities that are supportive, nurturing, gentle, and affirming, in ways they're able to accept and at times when they're ready. 
I have a lot of confidence that reflection is a very powerful way of promoting self-guided learning in life. ... I think one can help people to be ready for things [like this], but one can't force them. ... [I'd recommend] getting people close to nature, ...creating an enquiring mind, creating the space in which it's safe to enquire ... developing a range of retreat-type experiences which have stories, writing, drawing, performance - things which bring different capacities out from within ourselves. ... [It's about determining] what's going to get people more in touch with themselves and their sense of meaning.

One respondent is actually given annual, paid retreat leave by her employer (this is in addition to paid holiday leave). Her organisation includes pyscho-spiritual development as a component/topic of the employees' annual performance appraisal. In fact, this agency makes retreating very convenient as it has its own retreat centre and even lays on transport there and back. These two weeks' retreat leave are stipulated for inner work and care.

\section{DISCUSSION OF THE FINDINGS}

This study identifies the efficacy of retreating as a self-care tool among helping practitioners. Retreating reflects a time, a place, a purpose and a structure for interiority; for the inner work that sustains/restores a cohesive sense of self. Retreating is about paying attention to those aspects of oneself that are unnoticed, ignored or debilitated in the routine of daily life. It is about giving dedicated time to oneself, in an appropriate setting, so that one's multi-dimensionality can benefit - be it one's physical self, psychological self, social self, professional self, spiritual self, creative self and so on. Retreating makes self-care intentional and focused. It is more than merely an adaptive response to life's stresses. It is also a proactive choice for perso nal mastery: the choice to make the human experience a deeply meaningful one. As such, retreating serves important psychological needs.

The essential value of retreating lies in the time and opportunity it offers for intense application of various tools, undertaken with a specific purpose, within a very focused period, in a beautiful place, and a sacred space. Retreating is confirmed to be of preventative, rehabilitative, developmental, transcendental and professional benefit. The benefits are significant enough to warrant repeated effort, despite the difficulties associated with getting away for, enduring, or concluding a retreat and re-entering one's usual lifeworld. As is shown by the data, the regularity of self-care time enhances sustainability of the rewards, whilst the choice and combination of selfcare tools facilitates the journey to interiority.

The multiple and cumulative benefits of the retreat experience reinforce the motivation for continued retreating. Because self-care is a continuous process, were retreating to be removed as an option, the key practices and artefacts associated with the retreat experience would compensate - provided they are applied with greater regularity and attention.

The need for self-maintenance arises not only from the demands and pressures of one's external environment, but also from one's own personal ambitions, lifestyle, personality and responsibilities. Developing/maintaining the degree of personal and professional well-being needed in any human service agency is almost entirely the duty of the individual. Even where agencies recognise and respond to the need for "care-for-the-caregiver", the obligation for selfcare does not fall away. However, until organisations actively and continuously promote their staff's holistic wellness, self-care is likely to remain in the private domain and continue as a practice undertaken primarily outside normal working hours.

As an exploration of the meaning and importance of retreating as a self-care tool for helping practitioners, this study has noted several cautions embedded in its recommendations. 


\section{RECOMMENDATIONS}

Eight recommendations stem from the research.

1. Self-awareness and self-care practices should ideally be encouraged across society, from a young age, irrespective of whether one intends becoming a helping practitioner or not. This recommendation is made in recognition that the demands, pace and responsibilities of modern living - for children and adults alike - impact on well-being. Knowing how to recognise one's personal and professional stresses and needs, and attending to them, can be regarded as an essential life-skill.

2. It would benefit student helping practitioners - at tertiary level - to be taught a range of selfcare tools so that they enter the field equipped with the knowledge and skills necessary for personal wellness and professional competency; so that both worker and client benefits from the practitioner's reflexivity and intra-/inter-personal competencies. The tools specifically recommended are those of self-reflection, meditation and relaxation practices. Selfawareness/reflection is essential for many reasons:

- to recognise one's physical/psychological state/status before/during/after client interaction;

- to identify counter-transference as it emerges;

- to use one's skills and knowledge consciously, intentionally and beneficially for self and other;

- to enhance capacity for deep empathic understanding of the client's state;

- to identify when time-out/time-away is essential;

- to facilitate one's own growth across the multiple roles one has in life;

- to maintain/restore positive self-concept/esteem.

On the other hand, meditation offers benefits for the mental and/or spiritual dimension of well-being, and relaxation techniques promote physical wellness. Taken together, these three practices address mind-body-spirit well-being.

3. The self-care practices associated with retreating can be made more accessible through the right language. For example, removing the religious connotations of retreating expands its audience and more accurately reflects the non-denominational/secular emphasis of retreating. The tools used on retreating can even be promoted as techniques with wider application than merely self-care. For example, the study shows that meditation can be promoted as a thinking-skills tool, valuable for problem-solving.

4. Caregivers in particular, need to be encouraged to learn what activities and resources benefit their personal and professional self-care. This is especially important given that human services agencies still largely rely on their staff to monitor and address their own well-being.

5. Retreats can be undertaken for purposes of nurturing self, exploring self, or transcending self. Knowing why one is undertaking a retreat, and then attending to that purpose, en ables one to structure the retreat accordingly and thus get the most benefit from it.

6. Any self-care programme needs to match the practitioner's needs, interests, values, preferences, personality, lifestyle and philosophy. This recognises that people are unique individuals. Where the majority of care-giver/retreatants in this study express agreement for the value of certain confrontational self-care practices of retreating (such as meditation, 
silence, self-reflection, contemplation, journal writing - where the shadow side of oneself is often experienced/expressed) they also acknowledge that such practices can raise anxiety/discomfort for other helping practitioners who are needful of more nurturing/supporting/comforting self-care. Self-care thus needs to be undertaken at the right time, the right place and in the right way. Knowing if/when/why/how one is ready, willing and able to engage with retreat-type practices assists in meaningful and respectful self-care.

7. Employee-practitioners and employers of practitioners recognise that many simple yet significant steps could be taken to make the workplace a more nurturing, productive and humane environment in which heart and spirit are as critical and as valued as one's professional skills and knowledge. The study cites how uncomplicated initiatives - that, say, inspire staff, enquire as to their personal wellness, offer opportunities for creativity and wellbeing - meaningfully acknowledge that staff are much more than just units of labour.

8. Employers are likely to find greater employee support for staff-development practices that support and affirm employee well-being rather than practices that confront or question it. Enforced retreating (or aligned practices) would be counterproductive. However, among those who undertake retreats, they would greatly value it as part of their employment package. Retreatant care-givers recognise that it reduces stress, enhances productivity, promotes holistic well-being and improves professional practice - gains that are significant to any employer.

\section{REFERENCES}

BLOOM, S. 1997. Creating Sanctuary: toward the evolution of sane societies. New York: Routledge.

BRUNTON, P. 1984. Perspectives (posthumous): the notebooks of Paul Brunton. New York: Larson Publications.

CALLAWAY, T. 2001. Cops make a getaway. Newsmagazine (BC Edition), 28(21):44.

DELANEY, B. 1992. Silence, Simplicity, and Solitude: a guide for spiritual retreat by David A. Cooper, 1992. Magill Book Reviews, 1/8/1992.

DRIEDGER, S.D., McCLELLAND, S. \& KAR, R. 2001. Soul Searchers. MacLean's, 16/4/2001, 114(16):42.

HART, T. 2001. From information to transformation: Education for the evolution of consciousness. New York: Peter Lang.

HOUSDEN, R. 1995. Retreat: time apart for silence and solitude. New York: Harper Collins.

HUNTER, D., BAILEY, A. \& TAYLOR, B. 1998. Co-operacy: a new way of being at work. Halfway House: Zebra Press.

LOUDEN, J. 1997. The Women's Retreat Book - a guide to restoring, rediscovering, and reawakening your true self - in a moment, an hour, a day, or a weekend. New York: Harper Collins.

MONTGOMERY, C.L. 1991. The care-giving relationship: paradoxical and transcendent aspects. The Journal of Transpersonal Psychology, 23(2):91-104.

MOUNT, B.M., LAWLOR, W., \& CASSELL, E.J. 2003. Spirituality and Health: developing a shared vocabulary. Annals RCPSC, 35(5):303-307. 
Psychology Today 1993. 26(1):52.

RAHNER, K. 1967. Spiritual Exercise. London: Sheed \& Ward.

SCHOFIELD, R. 1927. Retreats: their value, method and organisation. London: Society for promoting Christian knowledge.

SEVENHUIJSEN, S. 2003. Principle ethics and the ethic of care: can they go together? Social Work/Maatskaplike Werk, 39(4):393-399.

UNDERHILL, E. 1990. The Ways of the Spirit. New York: Crossroad Publishing.

VAUGHAN, F. 1991. Spiritual issues in psychotherapy. The Journal of Transpersonal Psychology. 23(2):105-119.

WELWOOD, J. 2000. "Reflection and presence: the dialectic of awakening" in HART, T. \& NELSON, P.L. (eds) Transpersonal knowing: exploring the horizon of consciousness. New York: State University of New York Press.

WILKINS, P. 1997. Personal and professional development for counsellors. London: Sage.

Ms E Layton and Dr K Collins, Department of Social Development, University of Cape Town, South Africa. 